Chapter 11

\title{
Computer Image Analysis of Liver Biopsy Specimens in Patients with Heroin Abuse and Coinfection (Tuberculosis, HCV, HIV)
}

\author{
Ivan B. Tokin, Ivan I. Tokin and Galina F. Filimonova \\ Additional information is available at the end of the chapter
}

http://dx.doi.org/10.5772/52971

\section{Introduction}

The computer morphometry in histopathology is one of the most perspective directions in contemporary medicine including the hepatopathology. The potential advantages of measurement in histopathology have been recognized for many years [1]. The quantitative estimation has several advantages over conventional visual assessment such as objectivity and reproducibility [2]. The employment of modern optical equipment and special computer programs creates the possibilities for significant acceleration of quantitative analysis.

At present the computer morphometry has been rather intensively used to study liver changes of the patients with chronic viral hepatitis. The quantitative assessment of the fibrosis was performed mainly in chronic virus hepatitis $C[3,4,5,6,7.8,9]$.

Many investigators considered that the quantitative evaluation of hepatic fibrosis was mostly useful for assessing the origin, location and the stage of fibrosis. Using the morphometric analysis is also very important for the correct evaluation of repeated biopsies [10]. Some investigators studied the changes in liver fibrosis after the interferon therapy $[11,12,13]$. This technique can be used in future for therapeutic trials by the estimation of the agents inhibiting the fibrosis progression [7].

Rates of fibrosis progression differ markedly in patients with HIV/HCV co-infection [14, 15, 16]. The natural history of hepatitis $C$ virus infection in tuberculosis and in human immunodeficiency virus-infected patients has never been studied with the use of the computer morphometric analysis of liver fibrosis progression. In this chapter the changes of liver biopsies in patients with heroin abuse and infected by hepatitis $\mathrm{C}$ virus (HCV), human immunodefi- 
ciency virus (HIV), pulmonary tuberculosis (TB) were studied by the morphological and computer morphometric analysis.

\section{Patients and methods}

\subsection{Patients}

13 male patients with co-infection of pulmonary tuberculosis (TB), chronic viral hepatitis C $(\mathrm{HCV})$ and human immunodeficiency virus (HIV) were investigated during the study. All the patients used also the injections of heroin (Table 1).

The patients started their history as a rule from heroin using (mean duration -9.5 years) and later all of them acquired HCV (mean duration -7.1 years), HIV (mean duration -4.7 years) and TB at last (the duration of TB infection of the most part of patients was less than 1 year).

The diagnosis was established after careful examination of the patients: the anamneses of diseases and life, laboratory analyses, virological and morphological studies. Serum level of alanine aminotransferase (ALT) and aspartate aminotransferase (AST) was expressed. The upper limit of normal (ULN) of ALT was $41 \mathrm{U} / \mathrm{L}, \mathrm{AST}-31 \mathrm{U} / \mathrm{L}$.

\subsection{Histological evaluation}

To refine the diagnosis as well as for detection of the activity of pathological processes in the liver, aspiration biopsy was taken from all the patients. All liver biopsies were performed to the routine medical follow up program, using the standard Menghini procedure [17, 18]. Criteria for adequacy of the biopsy specimens included a core length of $10 \mathrm{~mm}$ and at least 5-6 portal tracts. So, only 9 biopsy specimens were used for further histological evaluation. Four biopsy specimens were fragmented and weren't used (Table 1). Samples were formalin-fixed and paraffin-embedded. Serial paraffin sections were cut at $5 \mathrm{mcm}$. Hematoxylineosin and tolluidine blue stains were used.

Each biopsy for necro-inflammatory activity and fibrosis was assessed by two hepatologists. Knodell Histology Activity Index (HAI) was used to grade histopathological lesions [19]. HAI was graded as minimal (scores 1-3), mild (scores 4-8), moderate (scores 9-12), or severe hepatitis (scores 13-18). METAVIR group scoring system was used for detecting the stage of fibrosis [20]. Fibrosis was staged on the scale from F0 to F4, as follows: F0 = no fibrosis, F1 = portal fibrosis without septa, F2 = few septa, F3 = numerous septa without cirrhosis, F4 = cirrhosis. Only single patient showed any signs of cirrhosis. Fibrosis was also staged by Ishak scoring system[21]. In the Ishak scoring system interface hepatitis (piecemeal necrosis), focal necrosis in the lobule, portal inflammation were scored from 0 to 4 , incomplete cirrhosis (bridging necrosis with occasional nodules) and cirrhosis were scored from 5 to 6. 


\begin{tabular}{|c|c|c|c|c|c|c|c|}
\hline \multirow{2}{*}{$\begin{array}{l}\text { Patient } \\
\text { number }\end{array}$} & \multirow{2}{*}{ Sex } & \multirow{2}{*}{ Age (years) } & \multirow{2}{*}{$\begin{array}{l}\text { Biopsy } \\
\text { number in } \\
\text { next tables }\end{array}$} & \multicolumn{3}{|c|}{ Duration of infections (years) } & \multirow{2}{*}{$\begin{array}{l}\text { Duration of } \\
\text { heroin } \\
\text { abuse } \\
\text { (years) }\end{array}$} \\
\hline & & & & TB & $\mathrm{HCV}$ & HIV & \\
\hline 1 & male & 26 & 1 & 1 & 8 & 1 & 7 \\
\hline 2 & male & 26 & fragment & 1 & 11 & 11 & 11 \\
\hline 3 & male & 27 & 7 & 1 & 1 & 1 & 3 \\
\hline 4 & male & 31 & 8 & 1 & 5 & 5 & 8 \\
\hline 5 & male & 31 & fragment & 1 & 2 & 2 & 4 \\
\hline 6 & male & 32 & fragment & 10 & 1 & 8 & 17 \\
\hline 7 & male & 33 & 9 & 12 & 9 & 13 & 15 \\
\hline 8 & male & 33 & 3 & 1 & 1 & 1 & 8 \\
\hline 9 & male & 34 & 6 & 3 & 18 & 3 & unknown \\
\hline 10 & male & 34 & 2 & 1 & 7 & 8 & 11 \\
\hline 11 & male & 36 & fragment & 8 & 13 & 1 & 13 \\
\hline 12 & male & 37 & 4 & 5 & 1 & 1 & 10 \\
\hline 13 & male & 39 & 5 & 1 & 16 & 6 & 16 \\
\hline
\end{tabular}

Table 1. Characteristics of patients with heroin abuse and co-infection of TB, HCV, HIV. The patients are arranged according to their age.

\subsection{Computer digital analysis}

Quantitative morphometric analysis was performed using an image analysis system consisting of a microscope (Leica DM 2500) with attached digital camera (Leica DFC 320 R2) and a computer. Serial pictures of biopsy slices of patients with co-infection were photographed by light microscope and were saved electronically. Serial microphotographs of biopsies were made by an objective $\mathrm{x} 20$. The further process was performed with the computer program Adobe Photoshop CS 5.0. Serial microphotographs were mounted to receive the general picture of liver biopsy (Figure 1). The digital image was converted into a binary image. The two-dimensional patterns were measured by direct pixels counting on the binary images under simultaneous visual control of the light microscopy.

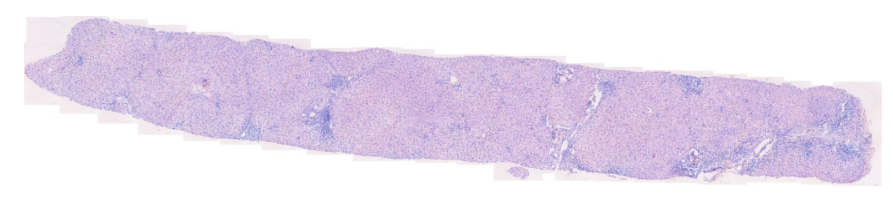

Figure 1. General picture of the liver biopsy composed by computer microscopy (Obj. x20) using Adobe Photoshop CS 5.0. Total area of the biopsy is 11449177 pixels

Three main parameters were used for quantitative evaluation: the total area of portal zones, the total area of intralobular infiltrates and necroses, as well as the total area of hepatic 
vessels (central and sublobular veins). We considered the total amount of these main parameters as non-parenchymal elements. Liver plates and sinusoids were attributed to the hepatic parenchyma.

The measurement of portions (in percentages) of portal area, foci of intralobular necroses, and vessels was estimated.

\subsection{Statistical analysis}

Statistical analysis was performed by tabulated processor Microsoft Excel 2003 and STATISTIKA 9.0.

\section{Results}

\subsection{Features of histopathological structure of biopsies}

Morphological analysis of liver biopsies of the patients - heroin addicts with tuberculosis (TB) and virus (HCV, HIV) co-infection showed that the extension of portal zones, the damage of limiting plates of liver cells and the formation of piecemeal and bridging necroses took place practically in all biopsies (Figure 2).
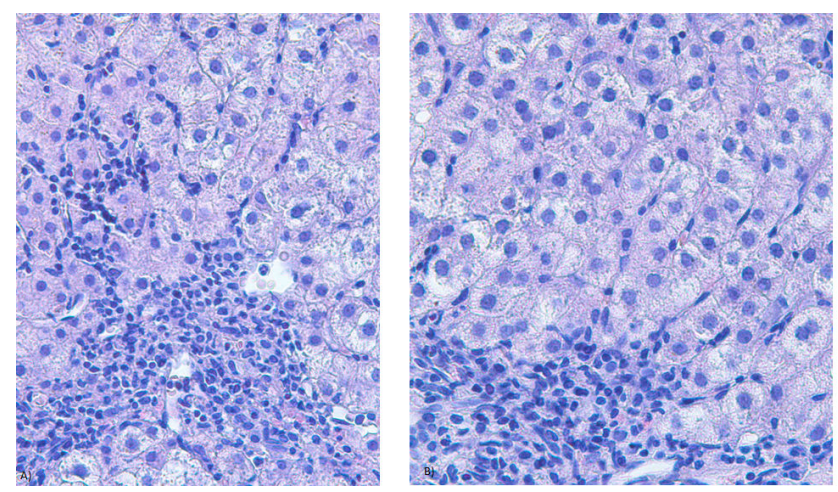

Figure 2. Subfigure with two images. Section of the liver biopsy specimen of a patient with co-infection (TB, HCV, HIV) and heroin abuse. Variants $(a, b)$ of the development of interface hepatitis with piecemeal necrosis at the peripheral zone of portal tract. Hematoxylin-eosin. Obj. x40

The peripheral regions of the portal zones were usually densely infiltrated by lymphocytes and mononuclear histiocytes (Figure 2). Sometimes the lymphoid aggregates adjacent to the damaged bile ducts were formed. Dense connective tissue elements developed more often around the portal vessels (portal veins and hepatic arteries). 
The appearance of focal lymphohistiocyte infiltrates and the formation of numerous intralobular necroses, containing hepatocytes, surrounded by lymphocytes (encircled hepatocytes) were typical to peripheral and middle zones of liver lobules (Figure 3).
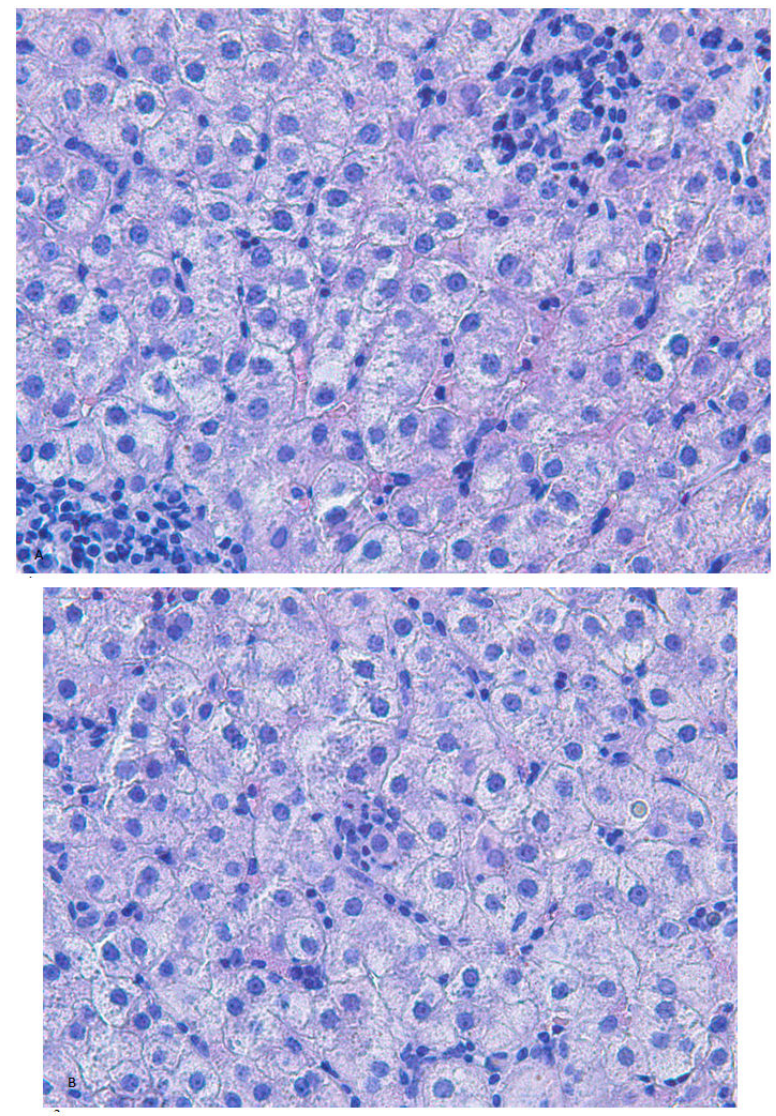

Figure 3. Subfigure with two images. Section of the liver biopsy specimen of a patient with co-infection (TB, HCV, HIV) and heroin abuse. Variants $(a, b)$ of the development of intralobular necroses containing encircled hepatocytes at the middle part of liver lobule. Hematoxylin-eosin. Obj. x40

In the liver parenchyma the narrowing of sinusoids, as without of inflammatory infiltration signs and with the elements of lymphohistiocyte infiltration and chains of lymphocytes inside of them, was predominated (Figure 4).

There were features of moderate protein and vacuole dystrophia in all biopsies. In two cases some hepatocytes contained large lipid inclusions (Figure 5). Disturbance of the lobular architecture was observed only in one biopsy (Figure 6). 


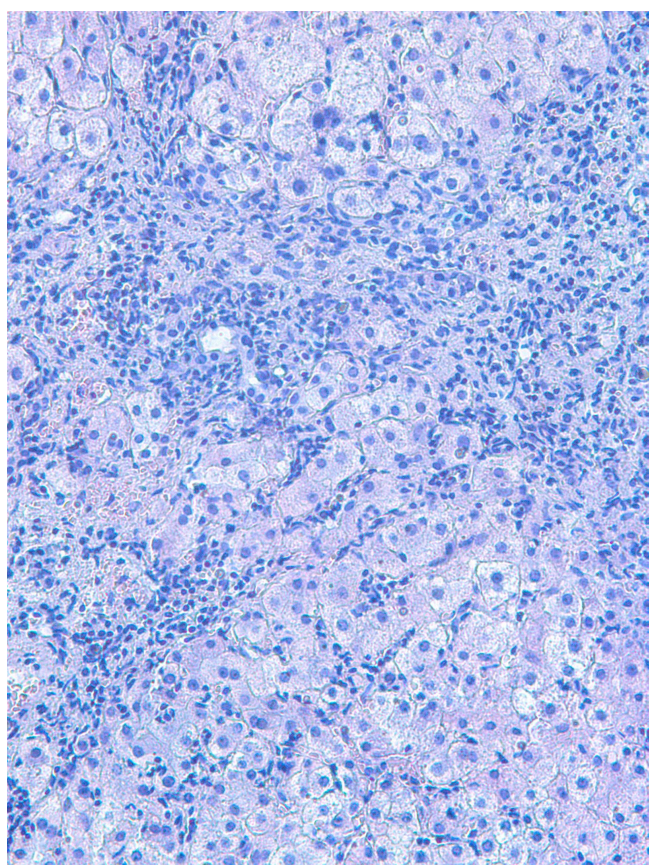

Figure 4. Section of the liver biopsy specimen of a patient with co-infection (TB, HCV, HIV) and heroin abuse. Severe infiltration of intralobular sinusoids by lymphocytes and histiocytes at the peripheral zone of liver lobule. Hematoxylineosin. Obj. $\times 20$

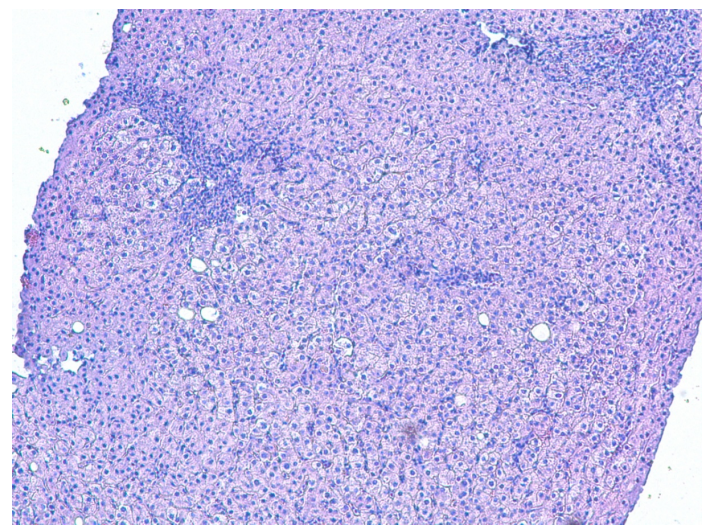

Figure 5. Section of the liver biopsy specimen of a patient with co-infection (TB, HCV, HIV) and heroin abuse. Expansion and infiltration of portal areas, presence of intralobular necroses at the middle zone of liver lobules, deposition of lipid droplets were in some hepatocytes. Hematoxylin-eosin. Obj. x10 


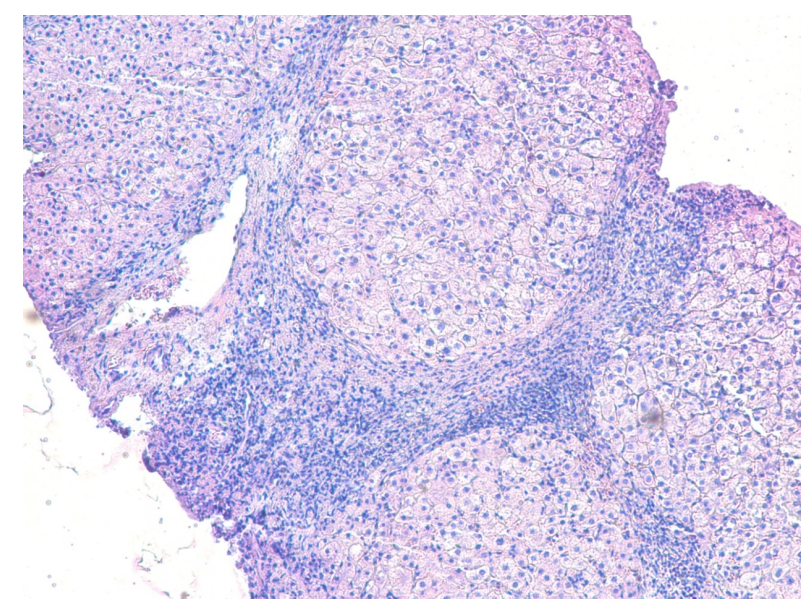

Figure 6. Section of the liver biopsy specimen of a patient with co-infection (TB, HCV, HIV) and heroin abuse. Strong development of bridging fibroses and disturbance of the lobular architecture. Hematoxylin-eosin. Obj. x10

\subsection{Quantitative image analysis for evaluation of pathological changes in liver biopsy structure}

Quantitative computer image morphometric analysis included three indexes. We calculated separately the square (in pixels) occupied by portal zones, the square of intralobular focal infiltrates and necroses and the square of hepatic vessels (central and sublobular veins).

The portal areas were divided into two groups: the portal zones with primary formation of piece-meal necroses and the portal zones with primary formation of bridging necroses. We took into account the calculation of portal zones fragments and septa. We also subdivided the intralobular damages in liver in two groups: the focal lymphohistiocyte infiltrates without hepatocytes and the intralobular piecemeal necroses with encircled hepatocytes.

As for hepatic vein, we separately considered terminal hepatic veins (central veins) and sublobular veins. In each case we estimated the relative square of the above-mentioned indexes in pixels and then calculated the specific parts in percents to the total square of biopsy.

We assigned the total sum of a specific part of portal zones, the specific part of intralobular focal infiltrates and necroses and the specific part of the hepatic veins as non-parenchymal elements. Respectively, the hepatic plates and sinusoids were remained in the composition of the parenchyma.

Then we calculated the parenchyma indexes as the relation of non-parenchymal elements to the parenchyma; these indexes characterized a certain degree of the replacement of the functioning hepatic tissue. 
The data obtained were summarized in the Tables 2, 4, 5, 6 and 7. The samples of biopsies were arranged in sequence of increasing of non-parenchymal elements in bioptats.

The control group included the analysis of cohort of the patients with the monoinfection of chronic virus hepatitis C (Table 3). The morphometric analysis of liver structure of the patients belonging to given group was made earlier with the use of the method of the stereometric point morphometry [8].

\subsubsection{The general characterization of morphometric data}

The analysis showed that the specific part of non-parenchymal elements strongly varied in the group of the patients with co-infection and heroin abuse: from $2.65 \%$ to $27.43 \%$ (Table 2). Mean value of non-parenchymal elements was $12.08 \pm 2.38$. The specific part of non-parenchymal elements varied in cases of monoinfection of hepatitis $\mathrm{C}$ with the different degree of activity from $2.16 \%$ до $11.93 \%$, the mean value was $6.94 \pm 0.77$. Thus, the mean value of nonparenchymal elements of liver biopsy of the patients - heroin addicts with co-infection exceeded the mean value of non-parenchymal elements in liver biopsy of the patients with monoinfection of hepatitis $\mathrm{C}(\mathrm{HCV})$ in 1.74 times. The maximal value of the specific part of non-parenchymal elements in case of co-infection was in 2.29 times higher than in cases of monoinfection HCV (Tables 2 and 3).

\begin{tabular}{|c|c|c|c|c|c|c|c|}
\hline $\begin{array}{l}\text { Biopsy } \\
\text { number }\end{array}$ & $\begin{array}{l}\text { Parenchymal } \\
\text { elements, \% }\end{array}$ & $\begin{array}{l}\text { Non-parenchymal } \\
\text { elements, \% }\end{array}$ & $\begin{array}{l}\text { Ratio of no } \\
\text { parenchym } \\
\text { elements }\end{array}$ & $\begin{array}{l}\text { - Total area } \\
\text { l of portal } \\
\text { zones, \% }\end{array}$ & $\begin{array}{l}\text { Total area } \\
\text { of spotty } \\
\text { infiltrates, } \\
\%\end{array}$ & $\begin{array}{l}\text { Total area } \\
\text { of hepatic } \\
\text { 'veins, \% }\end{array}$ & $\begin{array}{l}\text { Chains of } \\
\text { lymphocytes } \\
\text { (absent or } \\
\text { present) }\end{array}$ \\
\hline 1 & 97,35 & 2,65 & 0,03 & 1,86 & 0,52 & 0,27 & - \\
\hline 2 & 93,39 & 6,71 & 0,07 & 5,80 & 0,74 & 0,17 & + \\
\hline 3 & 93,07 & 6,93 & 0,07 & 6,43 & 0,21 & 0,27 & - \\
\hline 4 & 90,73 & 9,27 & 0,10 & 7,59 & 1,33 & 0,35 & + \\
\hline 5 & 90,52 & 9,48 & 0,10 & 7,93 & 0,46 & 1,08 & - \\
\hline 6 & 88,87 & 11,13 & 0,13 & 10,41 & 0,37 & 0,35 & + \\
\hline 7 & 83,72 & 16,28 & 0,19 & 14,52 & 1,53 & 0,53 & + \\
\hline 8 & 81,19 & 18,81 & 0,23 & 17,99 & 0,75 & 0,07 & + \\
\hline 9 & 72,57 & 27,43 & 0,38 & 27,16 & 0,31 & 0 & + \\
\hline
\end{tabular}

Table 2. Quantitative characteristics of liver biopsy specimens of patients with heroin abuse and co-infection of TB, HCV and HIV by computer morphometric analysis 


\begin{tabular}{|c|c|c|c|c|c|c|c|c|c|c|}
\hline $\begin{array}{c}\text { Biopsy } \\
\text { numbe } \\
r\end{array}$ & $\begin{array}{c}\text { ALT } \\
\text { activity } \\
\text { (U/L) }\end{array}$ & $\begin{array}{l}\text { Total area } \\
\text { of } \\
\text { morphomet } \\
\text { ry (points } \\
\text { of } \\
\text { intersection }\end{array}$ & $\begin{array}{c}\text { Total } \\
\text { number } \\
\text { of } \\
\text { microsco } \\
\text { pic } \\
\text { fields(SU) }\end{array}$ & $\begin{array}{c}\text { Parenchy } \\
\text { mal } \\
\text { elements, } \\
\%\end{array}$ & $\begin{array}{c}\text { Non- } \\
\text { parenchy } \\
\text { mal } \\
\text { elements } \\
, \%\end{array}$ & $\begin{array}{l}\text { Ratio of } \\
\text { non- } \\
\text { parenchy } \\
\text { mal } \\
\text { elements }\end{array}$ & $\begin{array}{c}\text { Total area } \\
\text { of portal } \\
\text { area, \% }\end{array}$ & $\begin{array}{c}\text { Total area } \\
\text { of spotty } \\
\text { infiltrates } \\
, \%\end{array}$ & $\begin{array}{l}\text { Total area } \\
\text { of hepatic } \\
\text { veins, \% }\end{array}$ & $\begin{array}{l}\text { Chains of } \\
\text { lymphocy } \\
\text { tes } \\
\text { (absent } \\
\text { or } \\
\text { present) }\end{array}$ \\
\hline & & s) & $(x 400)$ & & & & & & & \\
\hline 1 & 15, & 29450 & 95 & 97,84 & 2,16 & 0,02 & 1,79 & 0,05 & 0,32 & - \\
\hline 2 & 20 & 18910 & 61 & 97,54 & 2,46 & 0,03 & 2,00 & 0,25 & 0,21 & - \\
\hline 3 & 57 & 37690 & 126 & 96,49 & 3,51 & 0,04 & 2,30 & 0,46 & 0,75 & - \\
\hline 4 & 14 & 17980 & 58 & 96,40 & 3,60 & 0,04 & 3,18 & 0,01 & 0,42 & - \\
\hline 5 & 26 & 46190 & 149 & 95,70 & 4,30 & 0,04 & 3,15 & 0,12 & 1,02 & - \\
\hline 6 & 104 & 70060 & 226 & 95,37 & 4,63 & 0,05 & 3,25 & 0,30 & 1,09 & - \\
\hline 7 & 15 & 86800 & 280 & 95,30 & 4,70 & 0,05 & 2,91 & 0,02 & 1,77 & - \\
\hline 8 & 42 & 37820 & 122 & 94,94 & 5,06 & 0,05 & 3,81 & 0,26 & 1,00 & - \\
\hline 9 & 35 & 80290 & 259 & 94,82 & 5,18 & 0,05 & 3,93 & 0,84 & 0,41 & + \\
\hline 10 & 441 & 89900 & 290 & 93,36 & 6,64 & 0,07 & 3,29 & 2,02 & 1,32 & + \\
\hline 11 & 214 & 54560 & 176 & 91,33 & 8,67 & 0,09 & 7,24 & 0,89 & 0,55 & - \\
\hline 12 & 187 & 70680 & 228 & 90,54 & 9,46 & 0,10 & 7,57 & 1,76 & 0,13 & + \\
\hline 13 & 333 & 47720 & 152 & 90,32 & 9,68 & 0,11 & 7,51 & 1,17 & 1,00 & - \\
\hline 14 & 107 & 32860 & 106 & 90,29 & 9,71 & 0,11 & 8,32 & 1,02 & 0,37 & - \\
\hline 15 & 38 & 53514 & 193 & 89,44 & 10,56 & 0,12 & 6,23 & 2,61 & 1,71 & + \\
\hline 16 & 122 & 49600 & 160 & 89,11 & 10,89 & 0,12 & 9,07 & 1,27 & 0,54 & + \\
\hline 17 & 596 & 75330 & 243 & 88,24 & 11,76 & 0,13 & 9,26 & 1,56 & 0,94 & + \\
\hline 18 & 162 & 60760 & 196 & 88,07 & 11,93 & 0,14 & 11,49 & 0,44 & 0,00 & + \\
\hline
\end{tabular}

Table 3. Quantitative characteristics of liver biopsy specimens of the patients with monoinfection of chronic hepatitis C by stereometric point morphometry

We made the comparative analysis of histopathological changes in liver biopsy structure in the group of the patients - heroin addicts and co-infected using the standard semi quantitative methods of the Ishak score evaluation (Table 4).

We determined the histological activity index HAI according to Knodell [19]. The stages of the fibrosis development were defined by two ways: with the use of the research group French METAVIR [20] recommendations and with Ishak method [21]. Under the METAVIR system we evaluated the fibroses using five indexes where the maximal evaluation was 4 scores (F4 - cirrhosis). It consisted 6 scores (F6 - cirrhosis) according the Ishak system. 
Standard semi quantitative analysis methods for the most part of biopsies (6 patients from 9) made possible to determine the same fibrosis stage: F3 according to the Ishak system and F2 according to the METAVIR system (Table 4).

\begin{tabular}{ccccc}
\hline $\begin{array}{l}\text { Biopsy } \\
\text { number }\end{array}$ & $\begin{array}{l}\text { Non- } \\
\text { parenchymal } \\
\text { elements, } \%\end{array}$ & $\begin{array}{l}\text { HAl by score } \\
\text { Knodell }\end{array}$ & $\begin{array}{l}\text { Stage of } \\
\text { fibrosis by } \\
\text { score Ishak }\end{array}$ & $\begin{array}{l}\text { Stage of } \\
\text { fibrosis by } \\
\text { score } \\
\text { METAVIR }\end{array}$ \\
\hline 1 & 2,65 & 8 & $F 3$ & F2 \\
\hline 2 & 6,71 & 8 & $F 3$ & F2 \\
\hline 3 & 6,93 & 8 & $F 3$ & F2 \\
\hline 4 & 9,27 & 9 & $F 3$ & F2 \\
\hline 5 & 9,48 & 10 & $F 3$ & F2 \\
\hline 6 & 11,13 & 12 & $F 3$ & F2 \\
\hline 7 & 16,28 & 15 & $F 4$ & $F 3$ \\
\hline 8 & 18,81 & 11 & $F 3$ & $F 2$ \\
\hline 9 & 27,43 & 16 & $F 5$ & $F 4$ \\
\hline
\end{tabular}

Table 4. Comparative characteristics of non-parenchymal elements specific parts, grading of histopathological lesions ( $\mathrm{HAl}$ ) and the stages of fibrosis in liver biopsy specimens of the patients with heroin abuse and co-infection of TB, HCV and HIV by computer morphometry and semi quantitative evaluation

At that time the quantitative computer image morphometric analysis showed (Table 2) that among studied biopsies the specific parts of non-parenchymal elements differed significantly in various biopsies at the same fibrosis stages.

The minimal value of the specific part of non-parenchymal elements was $2.65 \%$. These values were $6.71 \%$ и $6.93 \%$ (two biopsy specimens), $9.27 \%$ and $9.48 \%$ (two other specimens of biopsy) and $11.13 \%$ (one biopsy specimen). Thus, in this case the methods of the semi quantitative score evaluation reflected only common regularities of the process of the fibrosis development. Meanwhile, the quantitative value of fibrosis was very essential for decision making of the medical treatment tactic and the estimation of the medical treatment effectiveness.

The quantitative value of fibrosis is especially important in the process of repeated studies for the determination of positive or negative dynamics of the fibrosis development. The histological activity index HAI according to Knodell proved to be more informative. HAI increased gradually from 8 to 16 points in accordance with the increasing of specific parts of non-parenchymal elements in biopsies. 


\subsubsection{Computer image analysis of portal zones}

The majority of non-parenchymal elements were situated in portal zones. Therefore these indexes were analyzed in details (Table 5).

\begin{tabular}{|c|c|c|c|c|c|c|c|c|c|c|c|}
\hline \multirow{2}{*}{$\begin{array}{l}\text { Biopsy } \\
\text { number }\end{array}$} & \multirow{2}{*}{$\begin{array}{c}\text { Total } \\
\text { area of } \\
\text { non- } \\
\text { parenchy } \\
\text { mal } \\
\text { elements, } \\
\%\end{array}$} & \multicolumn{2}{|c|}{$\begin{array}{l}\text { Total area of } \\
\text { portal zones }\end{array}$} & \multicolumn{4}{|c|}{ Portal area with piecemeal necroses } & \multicolumn{4}{|c|}{ Portal area with bridging necroses } \\
\hline & & & $\begin{array}{l}\text { Number } \\
\text { per } \\
\text { biopsy }\end{array}$ & $\begin{array}{c}\text { Total } \\
\text { area, \% }\end{array}$ & $\begin{array}{l}\text { Number } \\
\text { per } \\
\text { biopsy }\end{array}$ & $\begin{array}{l}\text { Minimal } \\
\text { size, \% }\end{array}$ & $\begin{array}{l}\text { Maximal } \\
\text { size, \% }\end{array}$ & $\begin{array}{c}\text { Total } \\
\text { area, \% }\end{array}$ & $\begin{array}{l}\text { Number } \\
\text { per biopsy }\end{array}$ & $\begin{array}{l}\text { Minimal } \\
\text { size, \% }\end{array}$ & $\begin{array}{c}\text { Maximal } \\
\text { size, \% }\end{array}$ \\
\hline 1 & 2,65 & 1,86 & 5 & 0,00 & 0 & 0 & 0 & 1,86 & 5 & 0,14 & 0,99 \\
\hline 2 & 6,71 & 5,80 & 13 & 2,98 & 5 & 0,10 & 0,86 & 2,82 & 8 & 0,10 & 1,23 \\
\hline 3 & 6,93 & 6,43 & 7 & 0,18 & 2 & 0,06 & 0,12 & 6,25 & 5 & 0,01 & 3,93 \\
\hline 4 & 9,27 & 7,59 & 9 & 4,94 & 4 & 0,16 & 2,38 & 2,65 & 5 & 0,14 & 0,97 \\
\hline 5 & 9,48 & 7,93 & 8 & 4,89 & 4 & 0,90 & 1,45 & 3,04 & 4 & 0,37 & 1,35 \\
\hline 6 & 11,13 & 10,41 & 12 & 0,62 & 2 & 0,19 & 0,42 & 9,79 & 10 & 0,16 & 2,92 \\
\hline 7 & 16,28 & 14,52 & 12 & 1,13 & 2 & 0,47 & 0,66 & 13,39 & 10 & 0,12 & 4,51 \\
\hline 8 & 18,81 & 17,99 & 5 & 7,92 & 4 & 1,17 & 3,37 & 10,07 & 1 & 0,01 & 10,07 \\
\hline 9 & 27,43 & 27,16 & 18 & 11,17 & 8 & 0,25 & 2,39 & 15,96 & 10 & 0,17 & 4,34 \\
\hline
\end{tabular}

Table 5. Quantitative characteristics of portal zones in liver biopsy specimens of the patients with heroin abuse and co-infection of TB, HCV and HIV by computer morphometric analysis

The amount of portal zones studied in each biopsy varied from 5 to 18 . It depended on the total biopsy volume. The mean value of the portal zones number was $9.89 \pm 1.34$. The amount of portal zones with piecemeal necroses varied from 2 to 8 (mean value was $3.44 \pm 0.72$ ). The amount of portal zones with the septa and bridging necroses was more significant, it changed from 1 to 10 (mean value was 6.44 \pm 1.01 ).

In one case (biopsy specimen № 8) the portal zone included several portal tracts forming the extensive confluent bridging necrosis.Thus, the amount of portal zones with bridging necroses (6.44) exceeded in 1.87 times the amount of portal zones with piecemeal necroses (3.44).

The total specific part of portal zones varied from $1.86 \%$ to $27.16 \%$ (mean value was 11.08 \pm 2.42 ) (Table 5).

The specific part of portal zones with piecemeal necroses varied from $0.18 \%$ to $11.17 \%$ (mean value was $3.76 \pm 1.21$ ). The minimal size of such portal zones characterized mainly its fragment, it changed from $0.06 \%$ to $0.9 \%$ (mean value is $0.37 \pm 0.13$ ). The maximal sizes of such portal zones characterized in general the degree of the portal zone extension, they changed from $0.12 \%$ to $3.37 \%$ (mean value was $1.29 \pm 0.37$ ). 
The specific part of the portal zones with bridging necroses (Table 5) changed from $1.86 \%$ to $15.96 \%$ (mean value was $7.31 \pm 1.63$ ). Thus, the specific part of portal zones with bridging necroses was practically in 2 times (1.94) more than the specific part of portal zones with piecemeal necroses.

The minimal size of portal zones with bridging necroses characterized in general the septa fragments, it changed from $0.01 \%$ to $0.37 \%$ (mean value was $0.13 \pm 0.03$ ). The maximal size reflected more correctly the specific part of the portal zones with bridging necroses, it changed from $0.97 \%$ to $10.07 \%$ (mean value was $3.37 \pm 0.91$ ).

The quantitative computer image morphometric analysis showed that the significant extension of portal zones with the destruction of the limiting plate and the development of piecemeal or bridging necroses took place in all bioptats of this patients group. In addition the specific part of portal zones with bridging necroses exceeded considerably (in 1.9 times) the specific part of portal zones with piecemeal necroses.

For comparison: the total specific part of portal zones changed from $1.79 \%$ to $11.49 \%$ (mean value was $5.35 \pm 0.68$ ) at chronic hepatitis C monoinfection (Table 3).

Thus, the specific part of portal zones of liver biopsies of the patients - heroine addicts with tuberculosis and virus (HCV, HIV) co-infection was 2.07 times higher than the specific part of portal zones of liver biopsies of the patients with the monoinfection HCV.

Moreover the bridging and piecemeal necroses were absent in the liver of the patients with monoinfection HCV under minimal and low activity. Their appearance was noticed only if

the value of specific parts of non-parenchymal elements exceeded $4.7 \%$.

We have not observed any difference between the amounts of piecemeal and bridging necroses in biopsy specimens with monoinfection $\mathrm{HCV}$.

\subsubsection{Computer image analysis of intralobular infiltrates and necroses}

We analyzed the morphometric indexes of intralobular infiltrates and necroses (Table 6).

Intralobular necroses presented in all biopsies, their number varied from 6 to 38 (mean value was $16.33 \pm 3.42$ ). The amount of focal intralobular lymphohistiocyte infiltrates was significantly less in comparison with the intralobular necroses containing encircled hepatocytes.

The total number of focal intralobular infiltrates varied in different biopsies from 1 to 11 (mean value was 3.67 \pm 1.09 ), whereas the total number of intralobular piecemeal necroses varied from 4 to 28 (mean value was $12.78 \pm 2.5$ ).

The relation between piecemeal necroses and focal intralobular infiltrates was especially demonstrative (Table 6). The number of piecemeal necroses in each biopsy was in several times more (up to 10 times) than the number of focal necroses. The total number of intralobular piecemeal necroses was 115 , whereas the number of focal intralobular infiltrates was only 33 , i.e. in 3.48 times less. 


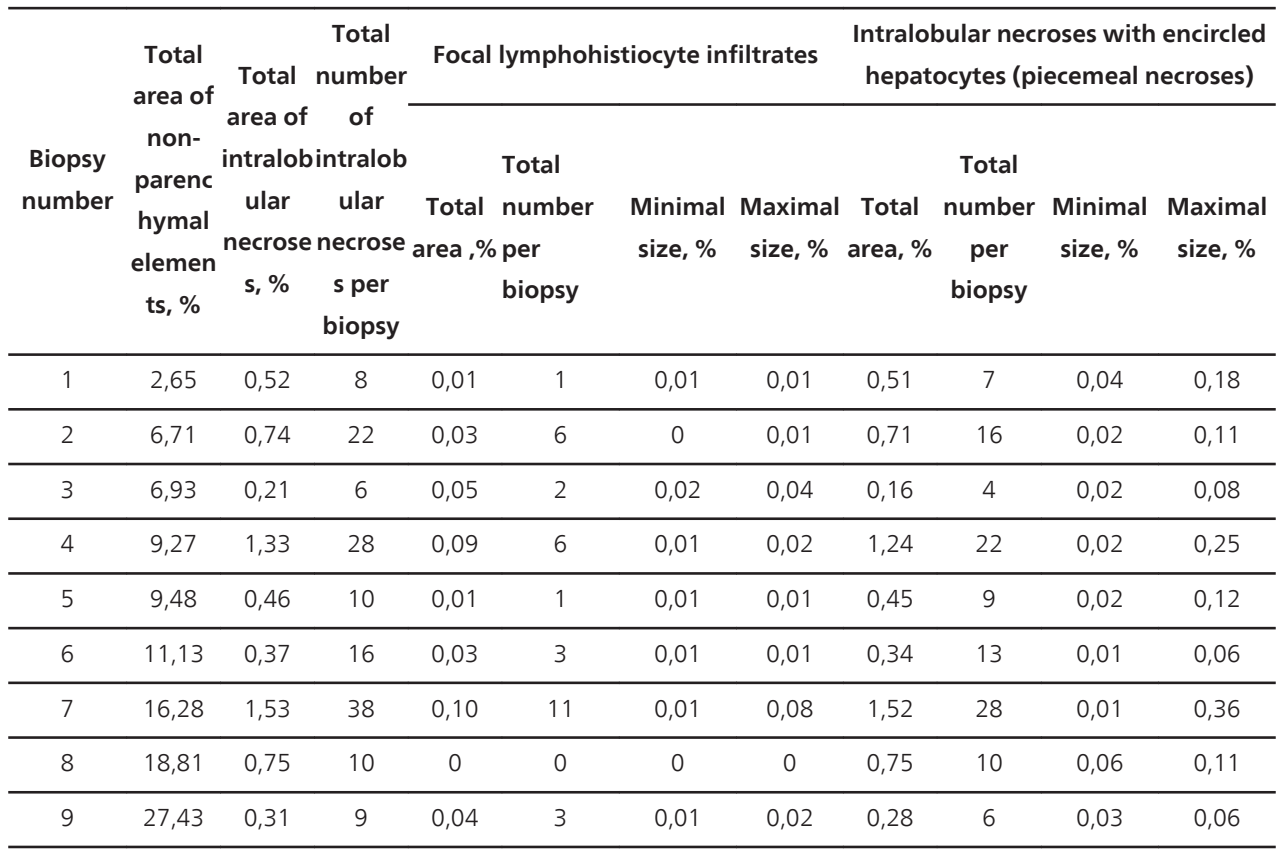

Table 6. Quantitative characteristics of intralobular necroses in the liver biopsy specimens of the patients with heroin abuse and co-infection of TB, HCV and HIV by computer morphometric analysis

The total specific part of intralobular necroses varied from $0.21 \%$ to $1.53 \%$ (mean value was $0.69 \pm 0.14$ ). The specific part of the focal intralobular infiltrates varied from $0.01 \%$ to $0.1 \%$ (mean value was $0.04 \pm 0.01$ ). The size of the minimal infiltrate was only $0.01 \%$, the size of the maximal infiltrate was $0.08 \%$ (mean value was $0.02 \pm 0.01$ ).

The total specific part of intralobular piecemeal necroses varied from $0.16 \%$ to $1.52 \%$ (mean value was $0.66 \pm 0.14$ ). The minimal size of the specific part of intralobular piecemeal necroses was $0.01 \%$ (mean value was $0.03 \pm 0.01$ ), whereas their maximal size was $0.36 \%$ (mean value was $0.15 \pm 0.02)$.

The analysis of the total biopsy specimen (Figure 1) allowed attributing the topography of the intralobular necroses distribution. Thus, under the middle degree of the parenchyma injury (HAI according to Knodell system up to 10 points) the small lymphohistiocyte infiltrates dominated in periportal zones of lobules. Under the high activity of the process (HAI according to Knodell scoring system exceeded 10 points) the large piecemeal necroses dominated, they arranged mainly in the middle zones of lobules.

Hepatocytes surrounded by lymphocytes were well noticeable in large piecemeal necroses (Figure $3 b$ ); it is perhaps connected with hepatocytes death, mediated by lymphocytes.

It is typically that the inflammatory infiltration of sinusoids and the formation "chains" of lymphocytes in them are mostly expressed in large piecemeal necroses (Figure 4). 
So, the histological activity index HAI according to Knodell reached 15 points, the total number of intralobular necroses reached 38 (28 from them were referred to piecemeal necroses) in the biopsy № 7 (Tables 4 and 6). Remarkably that during the cirrhosis development (biopsy № 9, fibrosis stage according to the METAVIR system scale was F4 - cirrhosis) the total number of intralobular necroses considerably reduced (6 piecemeal necroses and 3 focal infiltrates in one large biopsy; see Figure 6).

\subsubsection{Computer image analysis of hepatic vessels}

The amount of venous vessels in biopsy samples varied from 2 to 7 (mean value was $3.33 \pm 0.63$ ). The central veins with endothelium which are often damaged predominated in all biopsies (Table 7).

\begin{tabular}{|c|c|c|c|c|c|c|c|c|c|c|c|}
\hline \multirow{2}{*}{$\begin{array}{l}\text { Biopsy } \\
\text { number }\end{array}$} & \multirow{2}{*}{$\begin{array}{c}\text { Total } \\
\text { area of } \\
\text { non- } \\
\text { parenc } \\
\text { hymal } \\
\text { elemen } \\
\text { ts, \% }\end{array}$} & \multirow{2}{*}{$\begin{array}{c}\text { Total } \\
\text { area of } \\
\text { hepatic } \\
\text { vessels } \\
\%\end{array}$} & \multirow{2}{*}{$\begin{array}{c}\text { Total } \\
\text { number } \\
\text { of } \\
\text { hepatic } \\
\text { vessels } \\
\text { per } \\
\text { biopsy }\end{array}$} & \multicolumn{4}{|c|}{$\begin{array}{c}\text { Terminal hepatic veins (central } \\
\text { veins) }\end{array}$} & \multicolumn{4}{|c|}{ Sublobular veins } \\
\hline & & & & $\begin{array}{c}\text { Total } \\
\text { area ,\% }\end{array}$ & $\begin{array}{l}\text { Number } \\
\text { per } \\
\text { biopsy }\end{array}$ & $\begin{array}{l}\text { Minimal } \\
\text { size, \% }\end{array}$ & $\begin{array}{l}\text { Maximal } \\
\text { size, \% }\end{array}$ & $\begin{array}{c}\text { Total } \\
\text { area, \% }\end{array}$ & $\begin{array}{l}\text { Number } \\
\text { per } \\
\text { biopsy }\end{array}$ & $\begin{array}{l}\text { Minimal } \\
\text { size, \% }\end{array}$ & $\begin{array}{c}\text { Maximal } \\
\text { size, \% }\end{array}$ \\
\hline 1 & 2,65 & 0,27 & 4 & 0,27 & 4 & 0,09 & 0,11 & 0 & 0 & 0 & 0 \\
\hline 2 & 6,71 & 0,17 & 2 & 0,17 & 2 & 0,03 & 0,14 & 0 & 0 & 0 & 0 \\
\hline 3 & 6,93 & 0,27 & 3 & 0,27 & 3 & 0,03 & 0,18 & 0 & 0 & 0 & 0 \\
\hline 4 & 9,27 & 0,35 & 4 & 0,35 & 4 & 0,07 & 0,11 & 0 & 0 & 0 & 0 \\
\hline 5 & 9,48 & 1,08 & 5 & 0,13 & 4 & 0,02 & 0,05 & 0,95 & 1 & 0,95 & 0,95 \\
\hline 6 & 11,13 & 0,35 & 7 & 0,35 & 7 & 0,01 & 0,11 & 0 & 0 & 0 & 0 \\
\hline 7 & 16,28 & 0,53 & 3 & 0 & 0 & 0 & 0 & 0,53 & 3 & 0,04 & 0,31 \\
\hline 8 & 18,81 & 0,07 & 2 & 0,07 & 2 & 0,03 & 0,04 & 0 & 0 & 0 & 0 \\
\hline 9 & 27,43 & 0 & 0 & 0 & 0 & 0 & 0 & 0 & 0 & 0 & 0 \\
\hline
\end{tabular}

Table 7. Quantitative characteristics of hepatic vessels in liver biopsy specimens of the patients with heroin abuse and co-infection of TB, HCV and HIV by computer morphometric analysis

Sublobular veins were observed only in two biopsies, perhaps they did not get into biopsies because of large sizes in comparison with central veins.

The total specific part of the hepatic vessels varied from $0.07 \%$ to $1.08 \%$ (mean value was $0.34 \pm 0.1$ ). The specific part of the central veins varied from $0.17 \%$ to $0.35 \%$ (mean value was $0.18 \pm 0.04$ ). The minimal size of the central vein was $0.01 \%$ (mean value was $0.03 \pm 0.01$ ), the maximal size was $0.18 \%$ (mean value was $0.08 \pm 0.02$ ). The specific part of sublobular veins reached $1.48 \%$, maximal size $-0.95 \%$. 
On the whole it is possible to note the tendencies to the stable extension of vessels and the damage of its internal walls. In addition, the sharp narrowing of intralobular sinusoids adjacent to above mentioned vessels, took part in the contribution of the impairment of the processes of the microcirculation inside of liver lobules. Perhaps the worsening of microcirculation lead to the bypass ways of the circulation, this may be one of the reasons of bridging necroses development.

\subsection{Investigation of activity of alanin aminotransferase (ALT) and aspartate aminotransferase (AST)}

The measurement of liver enzyme activities (serum ALT and AST) are important for diagnosis and assessment of liver diseases in clinical practice. However, ALT levels fluctuate in chronic HCV infection and may fall into the normal range [22].The use of many medications have been associated with elevated ALT levels [23]. In chronic hepatocellular injury, ALT increasing is more typical than AST. However, when the fibrosis progresses, ALT activity typically declines, and the ratio of AST to ALT gradually increases [24], especially during the development of cirrhosis [25,26].

We observed the increasing of the ALT and AST levels practically among all the patients (Table 8).

\begin{tabular}{cccc}
\hline $\begin{array}{l}\text { Biopsy } \\
\text { number }\end{array}$ & $\begin{array}{c}\text { Activity of }(\mathbf{U} / L) \\
1\end{array}$ & Activity of AST (U/L) & $\begin{array}{l}\text { Ratio of } \\
\text { AST/ALT }\end{array}$ \\
\hline 2 & 90 & 48 & 0,53 \\
\hline 3 & 45 & 32 & 0,88 \\
\hline 4 & 140 & 42 & 0,93 \\
\hline 5 & 162 & 90 & 0,64 \\
\hline 6 & 48 & 179 & 1,10 \\
\hline 7 & 90 & 39 & 0,81 \\
\hline 8 & 88 & 68 & 0,75 \\
\hline 9 & 106 & 93 & 1,05 \\
\hline
\end{tabular}

Table 8. Activity of serum alanine aminotransferase (ALT) and aspartate aminotransferase (AST) in liver biopsy specimens of the patients with heroin abuse and co-infection of TB, HCV and HIV

So, the ALT level changed from 36 to 162 points (mean value was $89.4 \pm 13.45$ ). The AST level varied from 32 to179 points (mean value was $75 \pm 14.25$ ). The AST/ALT ratio varied from 0.53 to 1.10 points (mean value was $0.83 \pm 0.06$ ).

The mostly expressed increase of ALT and AST levels was discovered in the patients with the samples of biopsy having the specific part of non-parenchymal elements up to $10 \%$ (Ta- 
ble 8, samples of biopsies № 4 and № 5). As a rule the ferment activity rather reduced under the fibrosis intensification. The AST/ALT ratio was increased in 3 patients. In other cases it was closer to the upper border of the normal level.

We have not discovered any direct interconnections between the ferment activity levels and the sizes of the specific parts of intralobular necroses. The intralobular piecemeal necroses were dominant in this group of the patients; perhaps, the hepatocytes destruction was caused by the special mechanism of the cell death (apoptosis).

\section{Discussion}

Detailed information about natural history of HIV/HCV co-infection is discussed in special review article [27]. Some studies have suggested that human immunodeficiency infection modifies the natural history of hepatitis $C$ virus infection accelerating the progression of fibrosis and the development of cirrhosis [28, 29, 30, 31].

Co-infection $\mathrm{HCV} / \mathrm{HIV}$ is very often discovered among injecting drug users [32, 33]. Thus, it was shown that about $90 \%$ drug users (consumers of heroin) are infected by hepatitis $\mathrm{C}$ virus [34]. Intravenous heroin abuse induces significant morphological changes in liver tissue (vesicular changes, fatty changes, chronic hepatitis, cirrhosis), and the severity of these changes increases with years of heroin abuse [35]. Authors supposed that worsening of morphological changes in the liver happens mostly often because of a significantly reduced detoxification functions of the liver.

Espinal, Peréz, Baéz, Hénriguez et al. [36] analyzed the clinical aspects of the co-infection HIV and tuberculosis. Tuberculosis remains an important public health problem in the world that has been exacerbated by HIV epidemic, resulting in increased morbidity and mortality $[37,38]$. The pathogenesis and mechanisms of inflammation and accelerated fibrosis in co-infected patients are still poorly understood [28, 39].

At present investigation the peculiarities of patients with heroin abuse and co-infection (TB, $\mathrm{HCV}$ and HIV) were analyzed (see Table 1). All the patients were males of the age from 26 to 39 years (mean value was 32.2 years). The heroin abuse was the longest (mean value was 13.6 years). Patients with HCV-infection occupied the second position of disease duration (mean value was 7.1 years), than there were the patients with HIV-infection (mean value was 4.7 years) and finally the patients with TB-infection (mean value was 3.5 years). At last case the tuberculosis was discovered for the first time of 7 patients from 13 patients. It is characteristic that Mycobacterium tuberculosis was not discovered in phlegm of any patients under repeated analyses.

We could not detect any interconnections between the quantitative parameters of biopsy specimen getting with the use of computer microscopy and for the duration of above-mentioned observations.

Moreover the tendency to the diseases heaviness increasing is evident. The good example of this tendency is the biopsy specimen № 9: the duration of heroin abuse in this case com- 
posed 15 years, HIV - 13 years, TB -12 years and $\mathrm{HCV}-9$ years. In accordance with it the cirrhosis developed in the liver of this patient (see Figure 6) and the segment of non-parenchymal elements reached $27.43 \%$. Among them the specific part of portal zones was prevalent $(27.16 \%)$.

The other peculiarity was the presence of the same stage of fibrosis (namely fibrosis F2 by METAVIR scoring) and F3 (by Ishak scoring) in liver of the majority of the patients.

At that time the segment of non-parenchyma elements in liver of these patients varied from $2.65 \%$ to $11.13 \%$, and the specific part of the portal zones changed from $1.86 \%$ to $10.41 \%$. The detailed information about discussion questions and interpretation of liver biopsy assessment by grading and staging systems was presented in recent works [40, 41].

The typical changes included the destruction of limiting plate, the expansion of portal areas and the development of interface hepatitis, formation of short septa or bridging necroses. The image analysis allows calculating of portal zones areas and intralobular infiltrates in different fields of biopsy vision. The expansion of portal zones took place especially during the development of interface hepatitis. As a rule, intensive lymphohistiocyte infiltration predominates in such a type of portal zones.

The region of intralobular infiltrates strongly varies. Our investigation showed that intralobular infiltrates developed as a result of lymphocyte-mediated death of hepatocytes (apoptosis).

Earlier we studied the apoptosis in liver biopsy specimens of the patients with HCV with the use of the TUNEL method [42, 43]. TUNEL-marked cells looked as small groups similar to intralobular piecemeal necroses. All morphometric parameters were significantly higher in comparison with monoinfection HCV [8].

\section{Conclusion}

Morphometric image analysis gives a possibility to evaluate quantitative parameters of necro-inflammatory and fibrosis changes in liver biopsy of patients with mixed infections and heroin abuse.

It is characteristic that the combination of different infections leads to the progression of liver inflammation and the increasing of the portion of non-parenchymal elements as a total sum of portal areas, intralobular infiltrates and distended hepatic vessels.

The investigation showed significant intensification of necroinflammatory lesions. Lymphohistiocyte infiltration was typical both for portal zones and intralobular areas. These morphological indications could be connected with the change of the immune state of patients as a result of combine effect of bacterial, viral infections and heroin abuse. So, numerous factors have been associated with an increased risk of fibrosis progression in liver of such type of patients. 
Of course, it is necessary for more correct analysis to study the biopsies of the patients of several control groups with the sequential cut-off of the definite factors. We plan to carry out such investigation in future.

Quantitative analysis of digital images of total biopsies is indispensable to study the effectiveness of treatment tactics testing as the effect of therapy can be calculated as the percentage of morphological changes in biopsy.

\section{Author details}

Ivan B. Tokin ${ }^{1 *}$, Ivan I. Tokin ${ }^{2}$ and Galina F. Filimonova ${ }^{1,2^{*}}$

*Address all correspondence to: ivan.tokin@rambler.ru

1 St.-Petersburg State University, Russia

2 North-Western State Medical University named after I.I.Mechnikov, Russia

\section{References}

[1] Koss, L. G. (1982). Analytical and Quantitative Cytology. A Historical Perspectives. Analytical and Quantitative Cytology and Histolology, 4, 251-256.

[2] Hamilton, P., \& Allen, D. (1995). Morphometry in Histopathology. Journal of Patholo$g y, 175(4), 369-379$.

[3] Pilette, S., Rousselet, M., Bedossa, P., Chappard, D., Óberti, F., Rifflet, H., Maiga, M., Gallois, Y., \& Calès, P. (1998). Histopathological Evaluation of Liver Fibrosis: Quantitative Analysis vs Semi-Quantitative Scores. Comparison with Serum Markers. Journal of Hepatology, 28(3), 439-446.

[4] O’ Brien., N., Keating, N., Elderiny, S., Cerda, S., Keaveny, A., Afdhal, N., \& Nunes, D. (2000). An assessment of Digital Image Analysis to Measure Fibrosis in Liver Biopsy Specimen of Patients with Chronic Hepatitis C. American Journal of Clinical Pathology, 114(5), 712-718.

[5] Zaituon, A., Mardini, H., Awad, S., Ukabam, S., Makadisi, S., \& Record, C. (2001). Quantitative Assessment of Fibrosis and Steatosis in Liver biopsies from Patients with Chronic Hepatitis C. Journal of Clinical Pathology, 54(6), June, 461-465.

[6] Goodman, Z., Becker, R., Pockros, P., \& Afdhal, N. (2007). Progression of Fibrosis in Advanced Chronic Hepatitis C: Evaluation by Morphometric Image Analysis. Hepatology, 45(3), 886-894.

[7] Goodman, Z., Stoddard, A., Bonkovsky, H., Fontana, R., Ghany, M., Morgan, T., Wright, E., Brunt, E., Kleiner, D., Shiffmann, M., Everson, G., Lindsay, K., Dienstag, 
J., Morishima, C., \& the HALT-C Trial Group. (2009). Fibrosis Progression in Chronic Hepatitis C: Morphometric Image Analysis in the HALT-C Trial. Hepatology, 50(6), 1738-1749.

[8] Filimonova, G., Tokin, I. I., Tokin, I. B., \& Hussar, P. (2010). An Assessment of Morphometric Analysis in Liver Biopsy Specimens with Chronic Hepatitis C. Papers on Anthropology. Tartu, Estonia, XIX, 69-80.

[9] Tokin, I. B., Tokin, I. I., \& Filimonova, G. F. (2011). Quantitative Morphometric Analysis of Liver Biopsy: Problems and Perspectives. In: Liver Biopsy. Ed. By Hirokazu Takahashi, INTECHWEB.ORG, 137-154.

[10] Kage, M., Shimamatu, K., Nakashima, E., Kojiro, M., Inoue, O., \& Yano, M. (1997). Long-Term Evolution of Fibrosis from Chronic Hepatitis to Cirrhosis in Patients with Hepatitis C: Morphometric Analysis of Repeated Biopsies. Hepatology April , 25(4), 1028-1031.

[11] Manabe, N., Chevallier, M., Chossegross, P., Causse, X., Guerret, S., \& Trepo, Grimaud. G. (1993). Interferon-alfa 2b Therapy Reduces Liver Fibrosis in Cronic A, NonB Hepatitis: A Quantitative Histological Evaluation. Hepatology, December , 18(6), 1344-1349.

[12] Duchatelle, V., Marcellin, P., Giostra, E., Bregeaud, L., Pouteau, M., Boyer, N., Auperin, A., Guerret, S., Erlinger, S., Henin, D., \& Degott, C. (1998). Changes in Liver Fibrosis at the End of Alfa Interferon Therapy and 6 to 18 Months Later in Patients with Chronic Hepatitis C: Quantitative Assessment by a Morphometric Method. Journal of Hepatology, 29(1), 20-28.

[13] Caballero, T., Pérez-Milena, A., Masserolli, M., O', Valle. F., Salmerón, F., Del Moral, R., \& Sánches-Salgado, G. (2001). Liver Fibrosis Assessment with Semiquantitative Indexes and Image Analysis Quantification in Sustained-Responder and Non-Responder Interferon-treated Patients with Chronic Hepatitis C. Journal of Hepatology, 34(1), 740-747.

[14] Benhamou, Y., Di Martino, V., Bochet, M., Colombet, G., Thibault, V., Liou, F., Katlama, K., Poynard, T., \& and for the Multivir C Group. (2001). Factors Affecting Liver Fibrosis in Human Immunodeficiency Virus and Hepatitis C Virus Co-infected Patients: Impact of Protease Inhibitor Therapy. Hepatology, 34(2), August, 283-287.

[15] Martinez-Sierra, C., Arizcorreta, A., Diaz, F., Roldán, R., Martin-Herrera, L., PérezGuzmán, E., \& Girón-González, J. (2003). Progression of Chronic Hepatitis C to Liver Fibrosis and Cirrhosis in Patients Coinfected with Hepatitis C Virus and Immunodeficiency Virus. Clinical Infectious Diseases, 36(2), 491-498.

[16] Poynard, T., Mathurin, P., Ching-Lung, Lai., Quyader, D., Poupon, R., Tainturier, M. H., Myers, R., Muntenau, M., Ratziu, V., Manns, M., Arndt, V., Capron, F., Chedid, A., \& Bedossa, P. (2003). for the Panfibrosis Group. (A Comparison of Fibrosis Progression in Chronic Liver Diseases. Journal of Hepatology, 38(3), 257-265. 
[17] Menghini, G. (1958). One-Second Needle Biopsy of the Liver. Gastroenterology August), 0016-5085, 35(2), 190-199.

[18] Menghini, G., Lauro, G., \& Caraseni, M. (1975). Some Innovations in the Technic of the One- Second Needle Biopsy of the Liver. American Journal of Gastroenterology, 64(3), 175-180.

[19] Knodell, R., Ishak, K., Bkack, W., Chen, T., Graig, R., Kaplowitz, N., Kiernan, T., \& Wollman, J. (1981). Formulation and Application of a Numerical Scoring System for Assessing Histological Activity in Asymptomatic Chronic Active Hepatitis. Hepatology, 1(5), September/October, 431-435, 0270-9139.

[20] French METAVIR Cooperative Study Group. (1994). Intraobserver and Interobserver Variations in Liver Biopsy Interpretation in Patients with Chronic Hepatitis C. Hepatology, 20(1), 15-20.

[21] Ishak, K., Baptista, A., Bianchi, L., Callea, F., De Groote, J., Gudat, F., Denk, H., Desmet, V., Korb, J., Mac, Sween. R., Phillips, M., Portmann, B., Poulsen, H., Sheuer, P., Schmid, M., \& Thaler, H. (1995). Histological Grading and Staging of Chronic Hepatitis B. Journal of Hepatology, 22(6), 696-699.

[22] Inglesby, T., Rai, R., Astemborsky, J., Gruskin, L., Nelson, K., Vlahov, D., \& Thomas, D. (1999). A Prospective Community Based Evaluation of Liver Enzymes in Individuals With Hepatitis C after Drug Use. Hepatology, 29(2), 590-596.

[23] Green, R., \& Flamm, S. (2002). AGA Technical Review on the Evaluation of Liver Chemistry Tests. Gastroenterology, 123(4), 1367-1384.

[24] Kim, W., Flamm, S., Di Bisceglie, A., \& Bodenheimer, H. (2008). Serum Activity of Alanin Aminotransferase (ALT) as an Indicator of Health and Disease. Hepatology. , 47(4), 1363-1370.

[25] Williams, A., \& Hoofnagle, J. (1988). Ratio of Serum Aspartate to Alanin Aminotransferase in Chronic Hepatitis: Relationship to Cirrhosis. Gastroenterology. 0016-5085, 95, 734-739.

[26] Sheth, S., Flamm, S., Gordon, F., \& Chopra, S. AST/ALT Ratio Predict Cirrhosis in Patients with Chronic Hepatitis C Virus Infection. American Journal of Gastroenterology, $93,44-48$.

[27] Petrovic, L. (2007). HIV/HCV Co-infection: Histopathological Findings, Natural History, Fibrosis, and Impact of Antiretroviral Treatment: a Review Article. Liver International, 598-606.

[28] Mohsen, A. N., Eastbrook, P. J., Taylor, C., Portman, B., Kulasegaram, R., Murad, S., et al. (2003). Impact of Human Immunodeficiency Virus (HIV) Infection on the Progression of Liver Fibrosis in Hepatitis C Virus Infected Patients. Gut, 52(7), July, 1035-1040. 
[29] Rullier, A., Trimoulet, P., Neau, D., et al. (2004). Fibrosis is Worse in HIV/HCV Patients with Low-level Immunosuppression Referred for HCV Treatment than in HCV-matched Patients. Human Pathology, 35, 1088-1094.

[30] Kelleher, T., \& Afdhal, N. (2006). Assessment of Liver Fibrosis in Co-infected Patients. Journal of Hepatology, 44(1), S126-S131.

[31] Vallet-Pichard, A., \& Pol, S. (2006). Natural History and Predictors of Severity of Chronic Hepatitis C Virus (HCV) and Human Immunodeficiency Virus (HIV) Co-infection. Journal of Hepatology, 44, 528-534.

[32] Thomas, D. L., Shih, J. W., Alter, H. I., et al. (1996). Effect of Human Immunodeficiency Virus on Hepatitis C Virus Infection among Injecting Drug Users. Journal Infectious Diseases, 174, 690-695.

[33] Di Martino, V., Rufat, P., Boyer, N., Renard, P., Degos, F., Martinot-Peignoix, M., Matherov, S., Le Moins, V., Vachin, F., Degott, C., Valla, D., \& Marcellin, P. (2001). The Influence of Human Immunodeficiency Virus Coinfection on Chronic Hepatitis C in Injection Drug Users: a Long-term Retrospective Cohort Study. Hepatology December , 34(6), 1193-1199.

[34] Tennant, F. (2001). Hepatitis C, B, D and A: Contrasting Features and Liver Function Abnormalities in Heroin Addicts. Journal of Addictive Diseases, 20(1), 9-17.

[35] Ilic, G., Karadzic, R., Kostic-Banovic, L., \& Stojanovic, J. (2005). Chronic Intravenous Heroin Abuse: Impact on the Liver. Facta Universitats Series: Medicine and Biology, 12(3), 150-153.

[36] Espinal, M., Peréz, E., Baéz, J., Hénriguez, L., Fernández, K., Lopez, M., Olivo, P., \& Reingold, A. (2000). Infectiousness of Mycobacterium tuberculosis in HIV-1-infected Patients with Tuberculosis: a Prospective Study. The Lancet, 355(9200), January, 275-280.

[37] Sharma, S., Mohan, A., \& Kadhitavan, T. (2005). HIV-TB Co-infection: Epidemiology, Diagnosis and Management. Indian Journal of Medical Research. 0971-5916, 121, 550-567.

[38] Sterlig, T. R., Pham, P. A., \& Chaisson, R. E. (2010). HIV Infection-Related Tuberculosis: Clinical Manifestations and Treatment. Clinical Infectious Diseases, 50(3), May, S223-S230.

[39] Jones, R., Dunning, J., \& Nelson, M. (2005). HIV and Hepatitis C Co-infection. International Journal Clinical Practice., 59, 1082-1092.

[40] Theise, N. D. (2007). Liver Biopsy Assessment in Chronic Viral Hepatitis: a Personal, Practical Approach. Modern Pathology, 20(7), July 2006, S3-S14.

[41] Shiha, G., \& Zalata, K. (2011). Ishak versus MERAVIR: Terminology, Convertibility and Correlation with Laboratory Changes in Chronic Hepatitis C. In: Liver Biopsy. Ed by Hirokazu Takahashi, INTECHWEB.ORG, 155-170. 
[42] Tokin, I. B., Hussar, P., Filimonova, G., Hussar, U., Jarveots, T., Suuroju, T., \& Tokin, I. I. (2008). Features of the Liver Apoptosis in Patients with Chronic Hepatitis C Viral Infection (HCV). In: Proceedings of the $7^{\text {th }}$ International Cell Death Society Symposium "Targeting cell death pathway for human diseases", Shanghai Mega City, China, 127.

[43] Tokin, I. B., Hussar, P., Filimonova, G., Hussar, U., Jarveots, T., Suuroju, T., \& Tokin, I. I. (2009). Features of Liver Apoptosis in Chronic Hepatitis C Virus (HCV) Infection. Papers on Anthropology Tartu, Estonia., 1406-0140 , XVIII, 361-371. 